\title{
Is the aerosol emission detectable in the thermal infrared?
}

\author{
H.-D. Hollweg, ${ }^{1}$ S. Bakan, ${ }^{1}$ and J. P. Taylor ${ }^{2}$ \\ Received 29 June 2005; revised 23 November 2005; accepted 24 April 2006; published 4 August 2006.
}

[1] The impact of aerosols on the thermal infrared radiation can be assessed by combining observations and radiative transfer calculations. Both have uncertainties, which are discussed in this paper. Observational uncertainties are obtained for two FTIR instruments operated side by side on the ground during the LACE 1998 field campaign. Radiative transfer uncertainties are assessed using a line-by-line model taking into account the uncertainties of the HITRAN 2004 spectroscopic database, uncertainties in the determination of the atmospheric profiles of water vapor and ozone, and differences in the treatment of the water vapor continuum absorption by the CKD 2.4.1 and MT_CKD 1.0 algorithms. The software package OPAC was used to describe the optical properties of aerosols for climate modeling. The corresponding radiative signature is a guideline to the assessment of the uncertainty ranges of observations and models. We found that the detection of aerosols depends strongly on the measurement accuracy of atmospheric profiles of water vapor and ozone and is easier for drier conditions. Within the atmospheric window, only the forcing of downward radiation at the surface by desert aerosol emerges clearly from the uncertainties of modeling and FTIR measurement. Urban and polluted continental aerosols are only partially detectable depending on the wave number and on the atmospheric water vapor amount. Simulations for the space-borne interferometer IASI show that only upward radiation above transported mineral dust aloft emerges out of the uncertainties. The detection of aerosols with weak radiative impact by FTIR instruments like ARIES and OASIS is made difficult by noise as demonstrated by the signal to noise ratio for clean continental aerosols. Altogether, the uncertainties found suggest that it is difficult to detect the optical depths of nonmineral and unpolluted aerosols.

Citation: Hollweg, H.-D., S. Bakan, and J. P. Taylor (2006), Is the aerosol emission detectable in the thermal infrared?, J. Geophys. Res., 111, D15202, doi:10.1029/2005JD006432.

\section{Introduction}

[2] The Intergovernmental Panel on Climate Change [IPCC, 2001] dedicated a full chapter in its "Scientific Basis" report to the role of aerosols on climate. IPCC noticed that atmospheric measurements have lagged behind awareness of the importance of aerosols in climate. This is in particular true for observations in the thermal infrared (TIR).

[3] Compared to the diversity of aerosol types, only a few observations of the radiative effect of aerosols in the TIR have been conducted where the main focus was on mineral dust. However, there is no unique type of desert aerosol, but a large diversity depending on the Earth's soil, erosion, vegetation, etc. [Sokolik et al., 2001]. Thus Saharan dust is different from Asian or Australian dust. Furthermore, the size distributions of aerosols are altered during transportation. Haywood et al. [2003] found that the submicron size distribution of aged regional haze of biomass burning

\footnotetext{
${ }^{1}$ Max Planck Institute for Meterorology, Hamburg, Germany.

${ }^{2}$ Met Office, Exeter, UK.
}

Copyright 2006 by the American Geophysical Union. 0148-0227/06/2005JD006432\$09.00 aerosol could be fitted by three log- normal distributions near the origin. After transportation over $2500 \mathrm{~km}$ the mode for the larger particles was absent. Lidar measurements discovered multilayered structures of transported mineral aerosols aloft the northeast Atlantic [Léon et al., 2003].

[4] Aside from aerosol properties and composition, also knowledge of the refractive index of aerosols is poor. Highwood et al. [2003] modeled properties and direct effect of a strong outbreak of Saharan dust measured by the UK Met Office C-130 aircraft during Saharan Dust Experiment (SHADE). They found that the spectral signature observed by the Airborne Research Interferometer Evaluation System (ARIES) operated by the United Kingdom Met Office is attributed to the presence of dust. The choice of refractive index, the mass loading, and the altitude of the dust layer dominated the degree of agreement between observation and simulation.

[5] The number of observations of radiative effects in the TIR of non-mineral aerosols is rather small. Lubin and Simpson [1994] measured urban pollution trapped between temperature inversions in the Los Angeles basin and found up to $9 \mathrm{Wm}^{-2}$ increased downward longwave flux density. Spänkuch et al. [2000] estimated the downward radiative forcing at the surface by coarse biogenic 

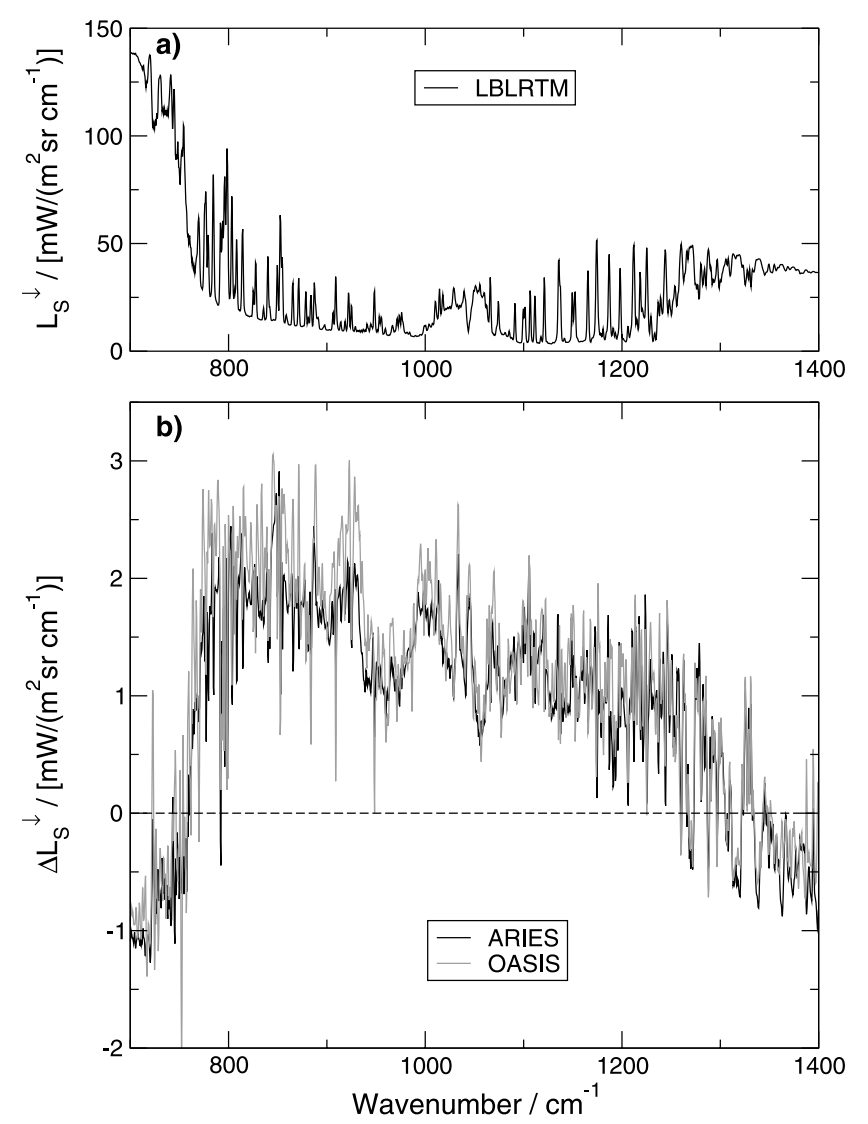

Figure 1. Residual zenith radiance of FTIR observations from LBLRTM (v9.3) model results. The simulation used the radiosonde profile from LACE on 9 August, 1648 UTC with the ozone profile from 10 August, 1045 UTC. (a) Radiance by LBLRTM. (b) Residual radiance by ARIES and OASIS from LBLRTM.

aerosols of pine pollen by $1-2 \mathrm{Wm}^{-2}$ with a maximum of $11 \mathrm{~mW} /\left(\mathrm{m}^{2} \mathrm{sr} \mathrm{cm}{ }^{-1}\right)$ at $1000 \mathrm{~cm}^{-1}$. Markowicz et al. [2003] analyzed data from the Aerosol Characterization Experiment (ACE-Asia) cruise of the NOAA research vessel Ronald H. Brown. They measured in clean marine air masses before and after a frontal passage and found optical depths of $0.03-0.05$ at $10 \mu \mathrm{m}$ before and a peak of 0.18 after the passage. The sampling near the Asian coast found both pollution and dust from the arid regions of Asia corresponding to the aerosol optical depth of 0.25 . Most of these observations were accomplished by FTIR systems.

[6] Figure 1 shows the residual of observations minus modeled clear-sky downward radiance at the surface for a radiosonde profile from the Lindenberg Aerosol Characterization Experiment (LACE) 1998 [Ansmann et al., 2002]. The observations are from the Ocean Atmosphere Sounding Interferometer System (OASIS) of the Max Planck Institute for Meteorology (MPI-M), Hamburg, and ARIES of the UK Met Office. The model is the Line-By-Line Radiative Transfer Model (LBLRTM) version 9.3 [Clough et al., 1992] initialized with radiosonde profiles taken during the FTIR measurements.

[7] This paper aims to determine whether such a residual can be attributed to aerosols in the atmosphere or whether uncertainties in the measurement and/or modeling could account for these differences. Thus this study investigates sources of uncertainties in deriving properties of aerosols in the TIR. In particular, the properties of downward radiation at the surface are discussed in connection with OASIS and ARIES. Those at the top of the atmosphere (TOA) are given for the Infrared Atmospheric Sounding Interferometer (IASI, http://www.esa.int/export/esaME/iasi.html). The models and data sources are introduced in section 2. In section 3, the Optical Properties of Aerosols and Clouds (OPAC) software package [Hess et al., 1998] provides the properties of atmospheric aerosols for climate modeling. These are used to characterize the expected radiative forcing both at the surface and TOA. In section 4 the accuracy of measurements by the ground-based interferometer systems ARIES and OASIS is discussed. A detailed look at the uncertainties of line-by-line (LBL) modeling is presented in section 5 for the uncertainties of the HITRAN 2004 line parameters [Rothman et al., 2005] and the difference due to the two algorithms CKD 2.4.1 [Clough et al., 1992] and MT_CKD 1.0 [Clough et al., 2005] describing water vapor continuum absorption. Uncertainties in the description of the atmospheric profiles of humidity and ozone concentration as input parameters of LBL calculations are also examined in section 6 and 7. The synthesis of all uncertainties determined is discussed in section 8 for the atmospheric window and is compared to the expected magnitudes of aerosol forcing. Finally, the uncertainties of radiative flux densities in three subintervals of the atmospheric window are presented in section 9.

\section{Models and Data}

[8] The observations used in this study were taken during the LACE field campaign [Ansmann et al., 2002] which took place in the summer of 1998 at the Meteorological Observation site at Lindenberg operated by the German Weather Service (DWD). The DWD provided radiosonde profiles several times per day. Also, 10 ozone sondes were launched between 3 and 12 August. Precipitable water vapor (PWV) was recorded by the Radiometrics ${ }^{(i M)}$ WVR1100 microwave radiometer. The standard atmosphere for summer at midlatitudes is used in the modeling studies to "top up" profiles to the TOA [McClatchey et al., 1978]. The ozone densities from ozonesondes nearest in time to the date of launch of the radiosondes are merged into the profiles. The profile recorded on 9 August, 1648 UTC, with ozone density taken on 10 August, 1045 UTC is denoted as the LACE atmosphere throughout this text. The atmospheric profiles used are given in Figure 2 where the profile from LACE is partially very dry above the planetary boundary layer (PBL).

[9] Radiance measurements were conducted by the two already mentioned Fourier Transform Infrared (FTIR) interferometer systems in the TIR. ARIES is usually mounted on an aircraft, but it operated ground-based side by side OASIS during LACE.

[10] Radiative transfer was calculated by two line-by-line models: the LBLRTM version 9.3 [Clough et al., 1992] and the model developed at the MPI-M [Hollweg, 1993]. LBLRTM applies the HITRAN 2000/2001 v11.0 database of line parameters and the MPI-M model additionally 


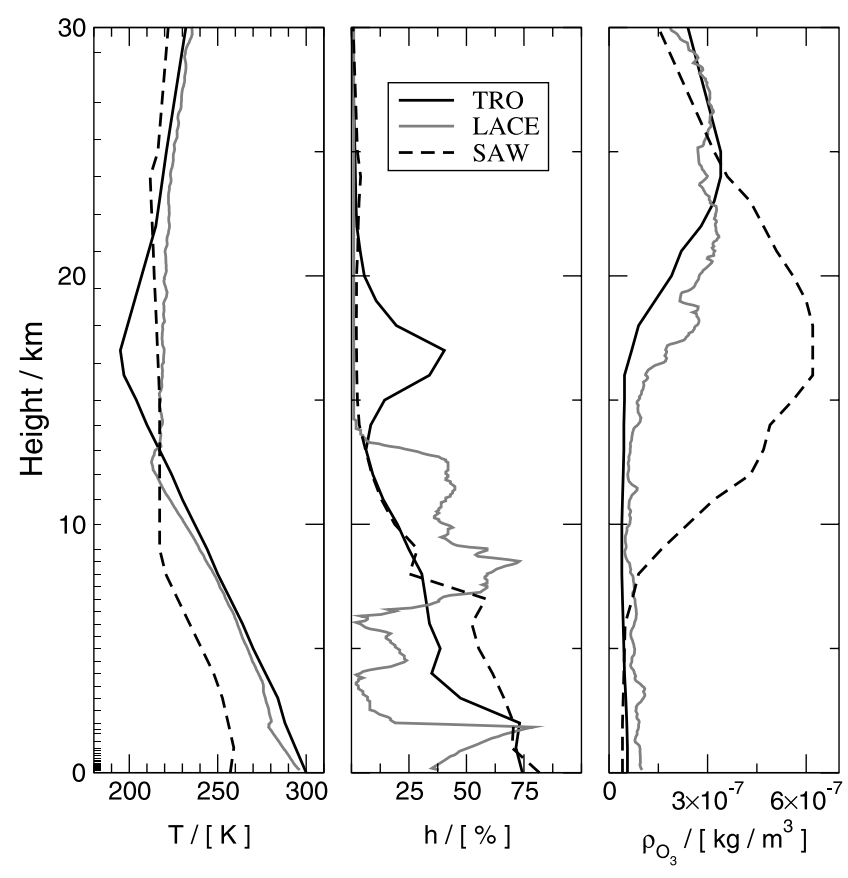

Figure 2. Profiles of temperature $\mathrm{T}$, relative humidity $\mathrm{h}$, and ozone density $\rho_{\mathrm{O}_{3}}$ for the standard atmospheres of the tropics (TRO), the subarctic winter (SAW), and from LACE on 9 August, 1648 UTC. The minor tick marks on the left most ordinate denote the vertical resolution used in the radiative transfer calculations.

applies the HITRAN 2004 version [Rothman et al., 2005]. The water vapor continuum absorption algorithms used were CKD 2.4.1 [Clough et al., 1989] and MT_CKD 1.0 [Clough et al., 2005]. The same vertical resolution was applied for both models; it is displayed in Figure 2 by the minor tick marks on the left most ordinate.

[11] The MPI-M model applies the averaged surface reflectivities in 12 bands in the TIR by Wilber et al. [1999]. The data is based on laboratory measurements of the spectral reflectance given in the Johns Hopkins Spectral Library (details in http://speclib.jpl.nasa.gov) for different mineral and vegetation types for 12 band-averaged spectral bands in the TIR. The types applied are evergreen broadleaf forest for the tropics, cropland/mosaic for the conditions at LACE (covered by one half grass, a quarter of conifer, and a quarter of deciduous), snow and ice for arctic conditions, quartz sand for the desert, seawater bodies, and blackbody emissivity for urban scenes.

[12] The OPAC software package provides easy access to the Global Aerosol Data Set [Hess et al., 1998]. The aerosol diversity is condensed to 10 components representing scenarios for climate modeling. The components can be mixed externally. Properties of extinction coefficient and optical depth for prescribed atmospheric distributions are given for 61 wavelengths between 0.25 and $40 \mu \mathrm{m}$.

[13] High-resolution spectra of modeled radiance are convolved with the Blackman-Harris apodization function with four terms (BH4) [Harris, 1978] corresponding to the instrumental function of OASIS and ARIES, respectively, and the one of IASI. OASIS and ARIES have a nominal resolution of about $0.48 \mathrm{~cm}^{-1}$ and a spectral resolution in terms of the Rayleigh criterion, i.e., resolving adjacent lines, of about $1 \mathrm{~cm}^{-1}$. The resolution for IASI is twice as high.

\section{Expected Radiative Impact of Aerosols in the TIR}

[14] Aerosol optical depths provided by the OPAC model are used to estimate radiance. The dynamic range of the extinction coefficients between the 10 components is much larger (about 6 orders of magnitude) than within the TIR spectrum for each individual component (about one order of magnitude). The optical depths of the aerosol mixtures for desert, transported mineral aloft, urban, and clean continental air are presented in Figure 3. The constituents, size distributions, and number concentration of the mixtures are those of Hess et al. [1998]. The transported mineral aloft case is a combination of a tropical maritime layer overlaying the surface and a layer with mineral above. All other types of aerosols reside in the PBL.

[15] The spectral optical depth given by OPAC is included in the line-by-line calculations by linear interpolation between the wave number points marked by the symbols in Figure 3. Then, it was converted into volume absorption coefficients appropriate for the thickness of the aerosol layer. The radiative forcing by aerosol is given by the difference from calculations without aerosols.

[16] The effect of some aerosol mixtures on radiative transfer is shown in Figure 4a for the zenith view at the surface and in Figure $4 \mathrm{~b}$ for the nadir view at TOA. The atmosphere from LACE was applied to the desert, urban, and continental aerosols. The transported mineral type is generally found over the (sub-)tropical ocean, thus the standard tropical atmosphere was used. The dynamic range of the radiance signature between the aerosol types desert

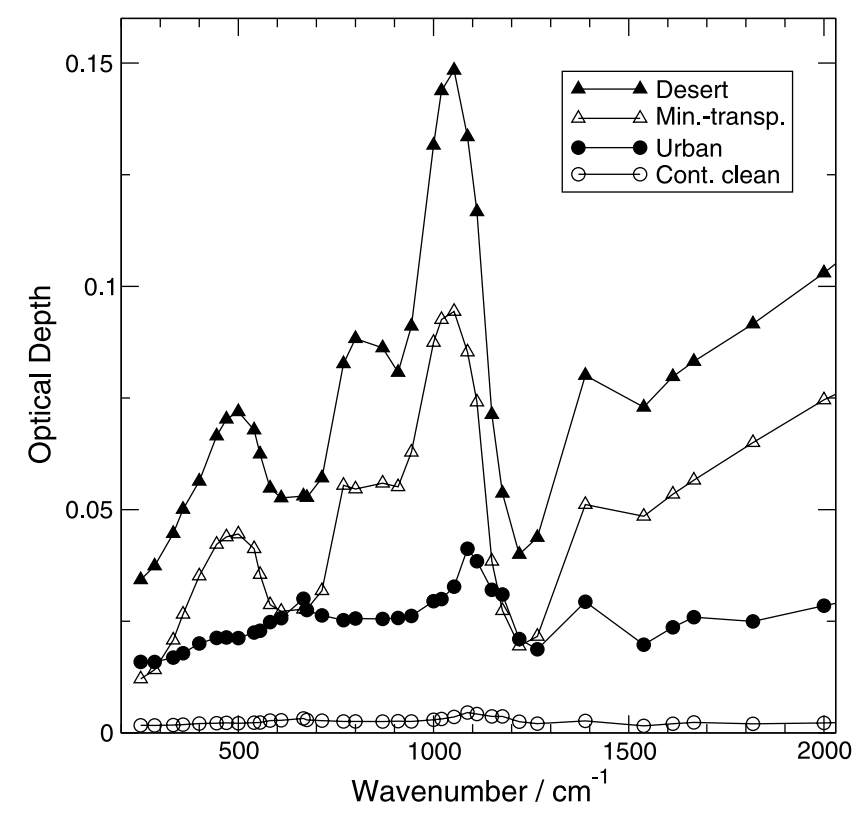

Figure 3. Optical depth of external aerosol mixtures provided by the OPAC software [Hess et al., 1998]. "Min.-transp." denotes transported mineral aerosol aloft and "Cont. clean." denotes continental aerosol for clean atmospheres. 

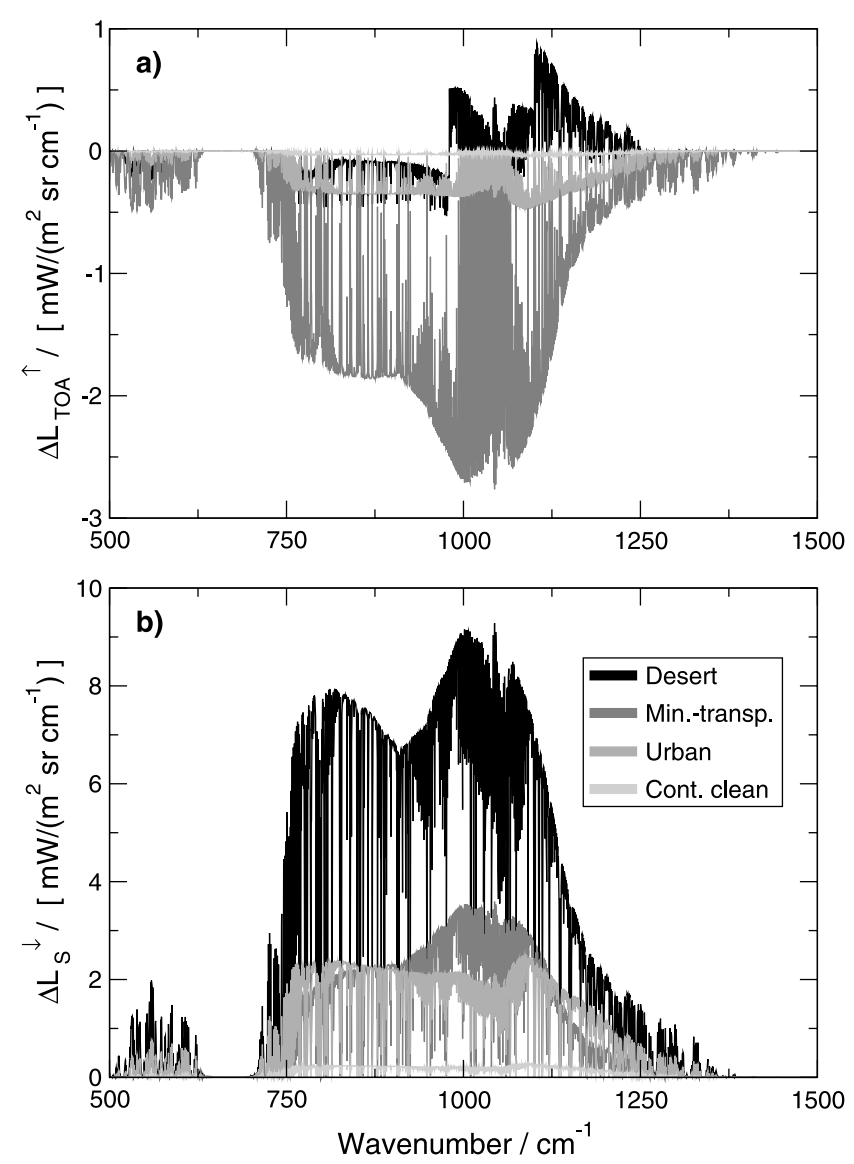

Figure 4. Radiative forcing by four aerosol mixtures provided by the OPAC software [Hess et al., 1998] included in line-by-line calculations. Atmosphere from LACE except tropical for the transported mineral aloft case. (a) Nadir upward radiance $\Delta \mathrm{L}^{\uparrow}$ at TOA. (b) Zenith radiance $\Delta \mathrm{L}^{\downarrow}$ at the surface.

and continental clean is evident in Figure 4a. The maximum of the aerosol optical depth about wave number $1050 \mathrm{~cm}^{-1}$ apparent in Figure 3 is affected by the $9.6 \mu \mathrm{m}$ ozone band.

[17] The vertical location of an aerosol layer matters for the radiative impact. A comparison of the effect by a layer with raised transported mineral to the one overlying the surface (the latter is not present in the figure) showed that the contribution from the layer aloft is decreased on its way down by the underlying water vapor. Looking at the impact on the upwelling radiation, the transported mineral aloft reduces outgoing longwave radiation (OLR) by a factor of seven stronger compared to the effect when located in the PBL.

[18] The impact of aerosols on upwelling radiation is complicated by the fact that downward radiation is reflected at the surface. If Earth radiated as a blackbody, aerosols would generally diminish outgoing longwave radiation. This is counteracted by the surface reflection, which redirects downward radiation generated by aerosols. Of course, decreased emissivity also decreases the amount of radiation emitted from the surface.

[19] The effect of surface reflection is shown in Figure 4b most evidently for desert aerosols by the changing sign. For blackbody emission, the spectral signature would be similar to the transported mineral case in the figure, apart from the magnitude. Apparently, the reflection of downward radiation by sand at the surface (over-) compensates the reduction of OLR by desert aerosol, in particular in the spectral ranges $980-1250 \mathrm{~cm}^{-1}$ with reflectivity higher than 0.1 .

[20] An extended study of the uncertainty of surface emission and its effect on aerosol measurements goes beyond the scope of this work considering different atmospheres, surface temperature, and emission models. Figure 4 represents the climatological radiative impact according to the OPAC software package as a guideline to the uncertainty assessments in section 8 .

\section{Accuracy of FTIR Measurements}

[21] The interferometer system ARIES is characterized by Wilson et al. [1999] and some details of OASIS are given by Bakan et al. [2001]. At its heart, ARIES has a commercial interferometer MR 200 and OASIS has a MR 154 developed by BOMEM, Inc., of Canada.

[22] The two interferometers are of a Michelson type with cube corner mirrors mounted on a double-pendulum and are equipped with two detectors, where the $\mathrm{HgCdTe}$ one is sensitive in the longer wavelength part of the TIR and the $\mathrm{InSb}$ detector is used for wavelengths shorter than $5.6 \mu \mathrm{m}$. In the case of ARIES, the two detectors are assembled as a sandwich-type. ARIES is cooled by a Stirling cycle cooler, whereas dewars have to be refilled for OASIS manually with liquid nitrogen.

[23] Non-linearity correction and apodization are processed similarly for the two instruments. However, OASIS spectra recorded at LACE required an additional removal of polarization effects due to a coated silver mirror used.

\subsection{Noise}

[24] Noise in interferometric systems is generated by the device and is amplified by the calibration process. It is composed of a systematic and a random contribution. The calibration of a measurement requires two additional recordings of targets with known radiance achieved by blackbodies radiating at different temperature. The calibration is accomplished by the procedure given by Revercomb et al. [1988].

[25] Wilson et al. [1999] express the noise performance of ARIES by noise-equivalent temperature difference $\mathrm{NE} \Delta \mathrm{T}$ for different numbers of coadded scans. They found for a coaddition representing an observation time about $1 \mathrm{~min}$ values of $\mathrm{NE} \Delta \mathrm{T}$ at $280 \mathrm{~K}$ of about $0.03 \mathrm{~K}$ for the spectral range 700 to $1200 \mathrm{~cm}^{-1}$. The spectral shape of the noise magnitude (resulting from the responsivity of the detector) is such that a minimum of $0.01 \mathrm{~K}$ occurs about the wave number of $900 \mathrm{~cm}^{-1}$.

[26] The frequency distribution of the OASIS noise obtained from laboratory blackbody measurements is shown in terms of radiances in Figure 5. Radiances according to the Planck function for the temperature of the blackbody have been subtracted from the calibrated spectrum. The number of calibrated files in the statistics was 20 and the spectral interval taken into account was $700-1300 \mathrm{~cm}^{-1}$ with the resolution of about $0.48 \mathrm{~cm}^{-1}$. 


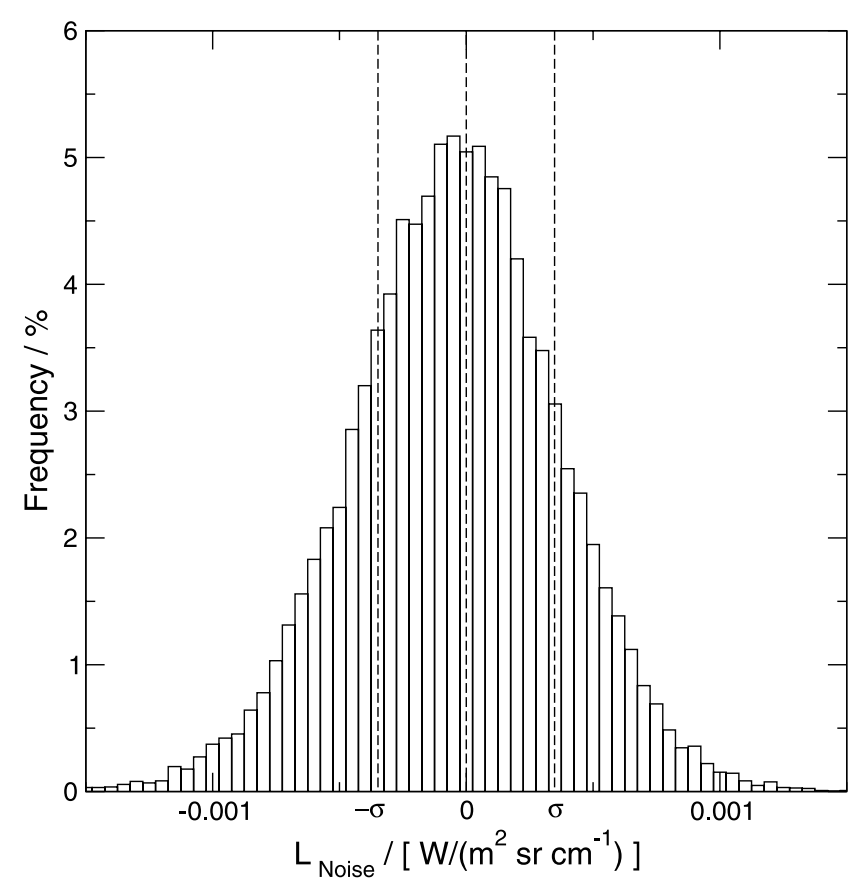

Figure 5. Frequency distribution of the noise of OASIS derived from cold blackbody measurements. The standard deviation $\sigma$ is denoted beneath the abscissa.

[27] The width of the frequency distribution, i.e., the range of noise, depends on the number of coadded scans. This particular one was derived for coadding 12 scans; the number also used for spectra presented in this text. The frequency distribution is almost centered, i.e., the mean almost vanishes, and the standard deviation is about $0.35 \mathrm{~mW} /\left(\mathrm{m}^{2} \mathrm{sr} \mathrm{cm}^{-1}\right)$. Rare peaks of more than $1 \mathrm{~mW} /$ $\left(\mathrm{m}^{2} \mathrm{sr} \mathrm{cm}^{-1}\right)$ of error may appear in spectra due to the noise. Deviations from the symmetry of a normal distribution would indicate systematic errors. Apparently, the latter are of minor importance. We note that the frequency distribution shown contains both the noise within the spectrum of each measurement and the noise between the measurements.

\subsection{Signal-to-Noise Ratio}

[28] The ratio of the expected radiative signal given by aerosols to the noise of OASIS can be used to estimate whether there is any chance to detect the signal by the instrument without statistical postprocessing. The impact on zenith radiance at the surface of four aerosol types was already shown in Figure 4a. The signal-to-noise ratio of these is given in Figure 6 applying the standard deviation of the noise of OASIS.

[29] The ratio for desert aerosol is high enough within the atmospheric window to be detected from a single measurement. The impact of the aerosols in clean continental air, of maritime air, and the arctic (the latter two are not shown) is smaller than the standard deviation of the noise. These can only be detected if various measurements are averaged and/ or averages are calculated for spectral ranges. Of course, the first method loses information about the time-dependent behavior of the atmosphere (and is not applicable for satellite borne observations at all) and the latter degrades the spectral resolution.

\subsection{Open-Field Comparison of ARIES and OASIS}

[30] The ARIES and OASIS instruments were compared under cloudless skies during the LACE campaign on 10 August 1998. A comparison of open field measurements requires either absolute synchronism or a stable atmospheric state. Because the calibration cycles of ARIES and OASIS differ, measurements were averaged for identical time slots of 20 min for ARIES and OASIS. The differences between these averages were calculated and averaged for a period of 7 hours. Figure 7 a shows the radiance spectrum for a single measurement by ARIES in the atmospheric window. The average of the differences between ARIES and OASIS spectra is shown in Figure $7 \mathrm{~b}$ and can be considered as measurement uncertainty between the two interferometers.

[31] The spectral uncertainty between OASIS and ARIES measurements is generally smaller than $0.5 \mathrm{~mW} /\left(\mathrm{m}^{2} \mathrm{sr} \mathrm{cm}{ }^{-1}\right)$ in the microwindows between stronger, isolated absorption lines which appear as spikes in the spectral differences. The spectrally averaged standard deviation between the two instruments, i.e., the noise within the bias, is about $\left.0.3 \mathrm{~mW} /\left(\mathrm{m}^{2} \mathrm{sr} \mathrm{cm}\right)^{-1}\right)$.

\section{Uncertainties in LBL Radiative Transfer Modeling}

[32] Solar radiation is the prime source and longwave radiation the sink of energy of the Earth system. Therefore with the beginning of climate modeling, radiative transfer models were subject to validation. The Intercomparison of Radiation Codes in Climate Models [Luther and Fouquart, 1984] revealed large discrepancies between the different types of models. Ellingson and Wiscombe [1996] discussed developments in the aftermath of the ICRCCM study.

[33] Line-by-line models achieve the highest accuracy, where the emphasis is put on rebuilding radiative transfer

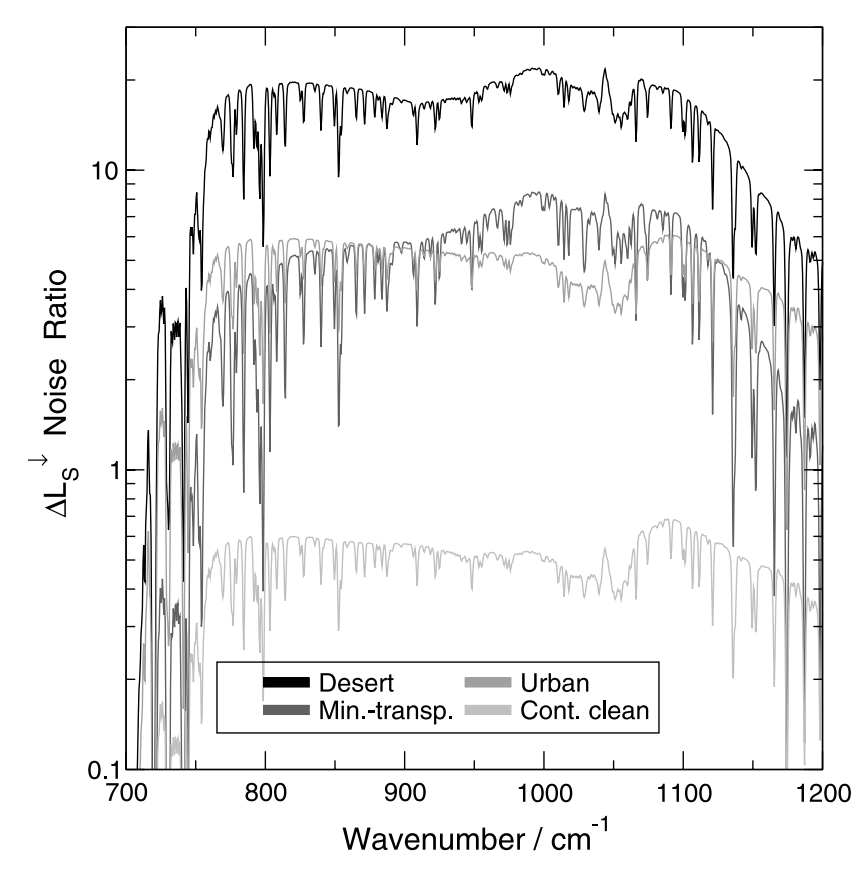

Figure 6. Ratio of the impact of aerosols on the zenith radiance at the surface to the standard deviation of the noise of OASIS. 

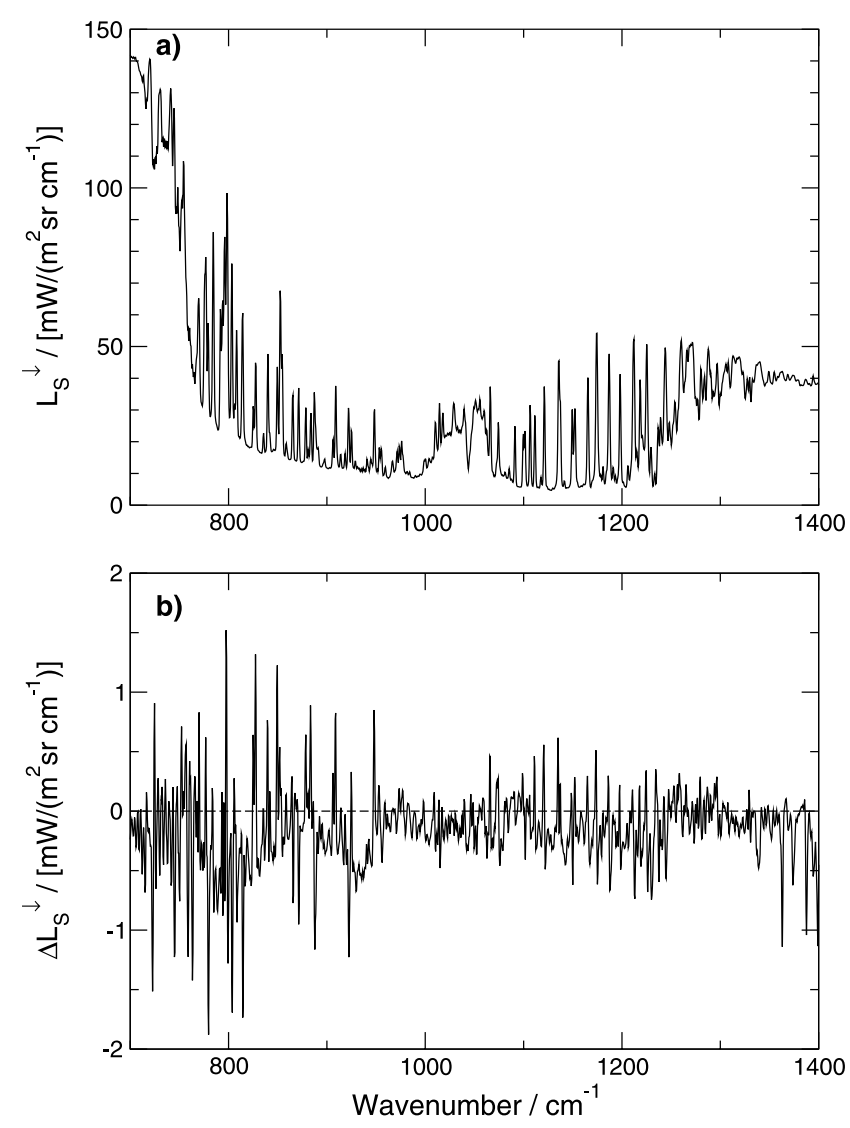

Figure 7. Comparison of ARIES and OASIS radiance spectra. (a) Zenith radiance at the surface by ARIES at LACE on 10 August, 1410 UTC. (b) The averaged difference of radiances of OASIS minus ARIES measured spectra at LACE during 1000-1700 UTC. Details in the text.

properties and not on computational speed. Ridgway et al. [1991] found agreement of $0.5 \mathrm{Wm}^{-2}$ at three levels between two LBL models calculating the ICRCCM test cases. Compared to these, Clough et al. [1992] found agreement within $1 \mathrm{Wm}^{-2}$ at most levels approaching $1.7 \mathrm{Wm}^{-2}$ at the surface for $\mathrm{F}^{\downarrow}$. They attribute the increased values to a different spectral sampling and different line parameters applied.

[34] More recently, upward results obtained by line-byline modeling were compared by Tjemkes et al. [2003] with regard to reproducing High Resolution Interferometer Sounder (HIS) observations in the CAMEX experiment and with ARIES measurements close to Ascension Island. They concluded that larger deviations occurred in the spectral range between 700 and $800 \mathrm{~cm}^{-1}$ and that a revision of the water vapor spectroscopic parameters in favor of the HITRAN 1996 data, used by most models, removed some fine scale biases between 800 and $1000 \mathrm{~cm}^{-1}$. Also, the inclusion of a realistic sea surface emissivity model was important for a realistic simulation in the $800-1000 \mathrm{~cm}^{-1}$ region.

\subsection{Uncertainties by the HITRAN Database}

[35] The uncertainties of the line parameters strength $\mathrm{S}$, half-width at half intensity $\gamma$, and position (the latter is not used in this work) are given in the HITRAN database [Rothman et al., 2005]. The error coding is partly descriptive as "unreported or unavailable," "default or constant," and "average or estimate." The most line parameters are attributed with numerical uncertainty ranges. In order to assess uncertainties of radiative transfer due to those of the line parameters, the descriptive coding was converted into numerical ranges based on a literature survey.

[36] The uncertainties of line parameters are given by classes with lower and upper boundaries in the error coding. These give a worser case and a less worse case of radiative uncertainties corresponding to the upper and lower boundaries of $S$ and $\gamma$. Uncertainties are given as unsigned values. Thus when combining the uncertainties of $\mathrm{S}$ and $\gamma$ in radiative transfer calculations, one has to care about the possibility of different signs. Maximum uncertainty is found, if uncertainties of S and $\gamma$ have the same sign and the upper boundaries of the error coding table are applied.

[37] How do uncertainties influence a single absorption line? An overestimation of $\mathrm{S}$ increases absorption in all parts of the absorption profile of a line. Reducing $\gamma$ decreases absorption in the wings of the profile but brings about an increase in the core. However, the impact by the uncertainty of $\gamma$ is reduced in the core whenever the Doppler broadening dominates.

[38] The uncertainty of radiance based on HITRAN 2004 line parameters was calculated line-by-line for the LACE atmosphere. The six main absorber $\left(\mathrm{H}_{2} \mathrm{O}, \mathrm{CO}_{2}, \mathrm{O}_{3}, \mathrm{~N}_{2}, \mathrm{CO}\right.$, and $\mathrm{CH}_{4}$ ), the MT_CKD 1.0 water vapor continuum absorption model and the NASA surface emissivity model were considered.

[39] The uncertainty of line parameters acts as a systematic bias in radiative transfer calculations depending on pressure, temperature, and absorber amount in the transmission function. In the limit of strong absorption, radiances are not affected much by the uncertainties of line parameters because the transmission function approaches zero (e.g., bands of $\mathrm{CO}_{2}$ at 15 and $4.3 \mu \mathrm{m}$ ). However, many medium absorption lines are present in the TIR causing higher radiative uncertainties.

[40] Uncertainties with the lower boundaries of the HITRAN error table applied are given in Figure 8 for the brightness temperature $T_{B}$ at TOA and for $\mathrm{L}^{\downarrow}$ at the surface. The uncertainty range of monochromatic calculations is shown in gray. The black curves represent spectra convolved with the BH4 apodization corresponding to the instrumental function of OASIS at the surface and the one of IASI for a space-borne interferometer.

[41] Outside the atmospheric window, i.e., outside of Figure 8, the uncertainties are highest in the absorption bands for nadir viewing from space. For the zenith view at the surface, the uncertainty vanishes in the strong bands, because of "saturated" absorption. In both cases, detection of aerosols is problematic.

[42] Figure 8 is representative for the atmospheric window where numerous microwindows appear. The magnitudes in the lines are larger for the line-by-line calculations than for the convolved spectra. The line-by-line calculated absolute value of the uncertainty in the centers of the water vapor lines is up to $0.4 \mathrm{~K}$ brightness temperature in the nadir for IASI and it is up to $3 \mathrm{~mW} /\left(\mathrm{m}^{2} \mathrm{sr} \mathrm{cm}{ }^{-1}\right)$, except a few 

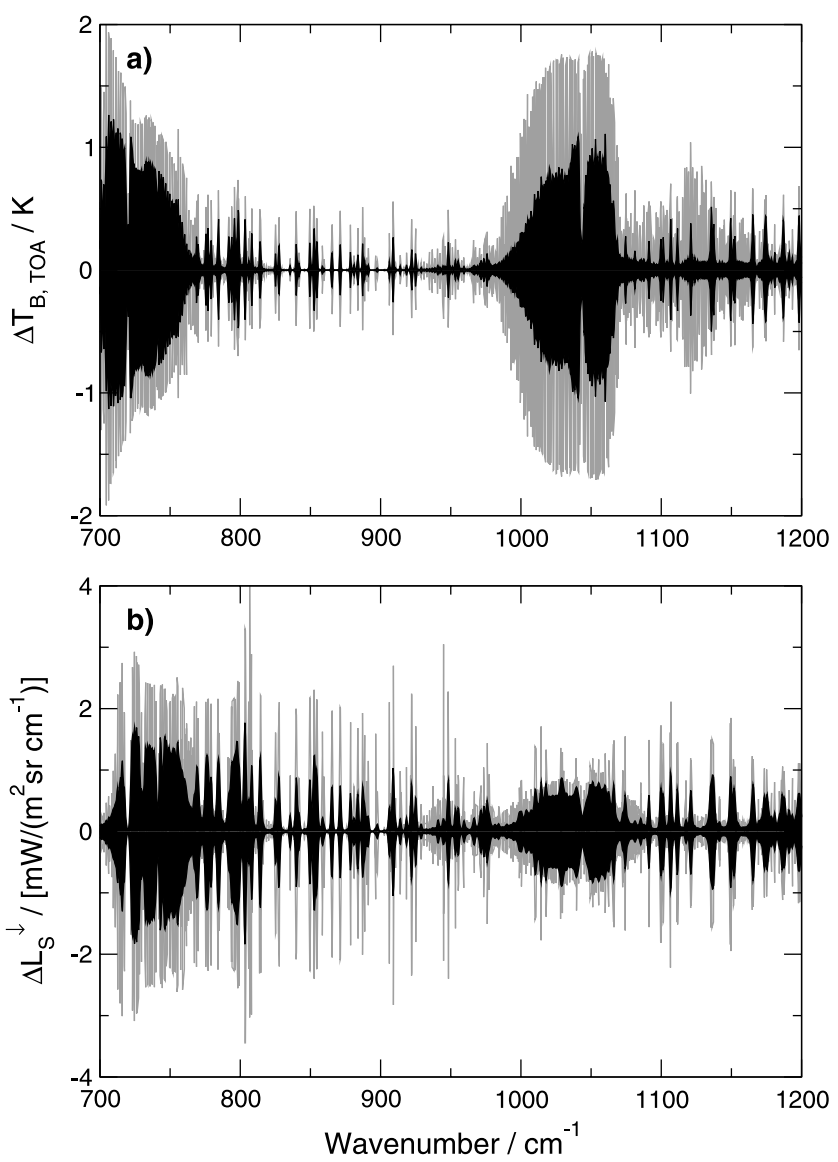

Figure 8. Uncertainty of radiative transfer due to the HITRAN error coding with the lower boundaries applied. Atmosphere from LACE on 9 August, 1648 UTC. Line-byline calculated uncertainty range in gray and the black range after the convolution with the Blackman-Harris 4 terms function. (a) Nadir brightness temperature at TOA with the convolution for IASI. (b) Zenith radiance at the surface with the convolution for OASIS.

lines around $805 \mathrm{~cm}^{-1}$, for the zenith radiance by OASIS and ARIES, respectively.

\subsection{Water Vapor Continuum Absorption}

[43] Absorption is not characterized appropriately in the atmospheric window by the Voigt profile. The water vapor continuum absorption (WVCA) is usually taken into account by the semiempirical model described by Clough et al. [1992]. The so-called CKD [Clough et al., 1989] model was updated several times considering new observations. A major update, the MT_CKD 1.0 continuum, was released recently based on a new formulation and the first recomputation of the entire continuum since the original. It is implemented into LBLRTM_v7.01 [Clough et al., 2005].

[44] Elaborating the radiative changes replacing CKD by MT_CKD is made difficult by the fact that Clough et al. [1992] ". . . have defined the continuum as that contribution to the molecular absorption coefficient that must be added to the line-by-line contribution ... to provide a result that is consistent with measurements. In the CKD model (and MT_CKD, too) the line-by-line contribution is taken as the Voigt profile out to $\pm 25 \mathrm{~cm}^{-1}$ from line center with the value at $\pm 25 \mathrm{~cm}^{-1}$ subtracted from all values of the Voigt profile within that spectral domain." Consequently, the continuum algorithm is inextricably linked to the line parameters database used for the derivation. For CKD this is HITRAN 1996 and HITRAN 2000/2001 was used for MT_CKD. The WVCA model then accounts for all deviations from the Voigt profile.

[45] A reasonable approach to obtain the effect of changing from CKD to MT_CKD is using the same database (here HITRAN '00/01) in conjunction with both the CKD and the MT CKD algorithm. However, in case of CKD, the Voigt profile basis $\left(\Delta \nu= \pm 25 \mathrm{~cm}^{-1}\right)$ of the HITRAN' 96 line parameters has to be subtracted from the absorption coefficients formed by the HITRAN 00/01 lines because CKD includes this basis. Correspondingly, the basis of the HITRAN 00/01 lines has to be subtracted in case of MT_CKD. The spectral difference of downward radiance at the surface of MT_CKD 1.0 minus that with CKD 2.4.1 calculated this way is presented in Figure 9 for the atmospheric window. Besides water vapor, also the five other main atmospheric absorbers have been taken into account. The surface was assumed to radiate as a blackbody.

[46] The biggest change by the new continuum algorithm is found for the tropical atmosphere. Zooming into a maximum of deviation would reveal that there is almost no change in the line centers due to close saturation. The major changes are found in the microwindows between the centers. The effect for the subarctic and the LACE atmosphere is not only less than for the tropics but also mainly positive, i.e., MT_CKD provides higher absorption, whereas for the tropics, smaller wave numbers of the atmospheric

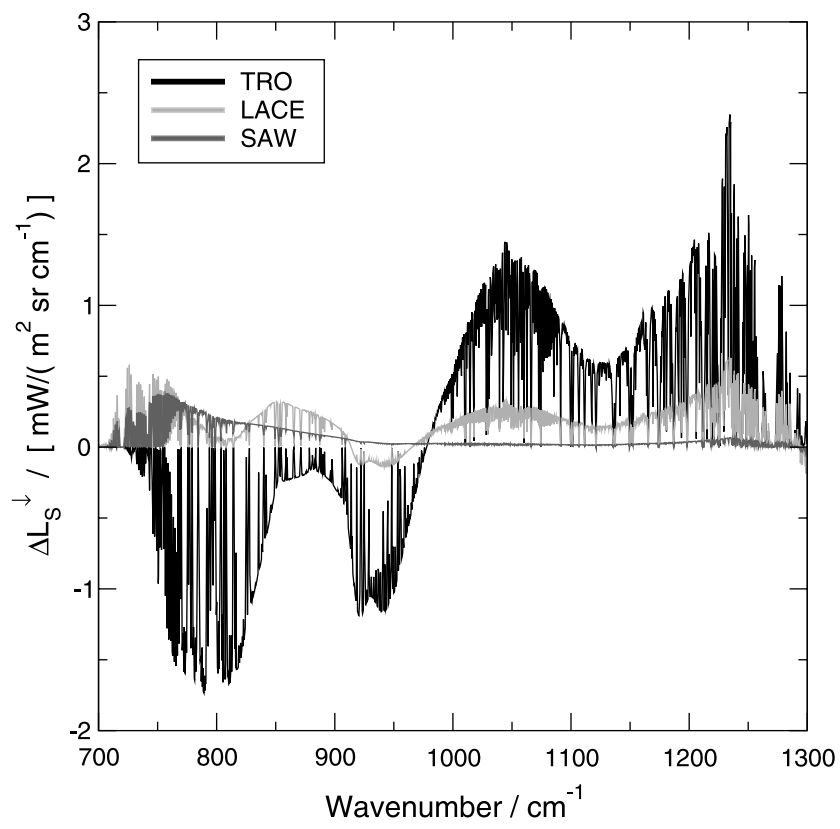

Figure 9. Difference of downward radiance at the surface calculated line-by-line applying the MT CKD 1.0 water vapor continuum absorption minus the CKD 2.4 based results. Atmospheres considered are tropical (TRO), at Lindenberg on 9 August, 1648 UTC (LACE), and subarctic winter (SAW). 
window exhibit less absorption compared to CKD 2.4.1 and higher absorption beyond $1000 \mathrm{~cm}^{-1}$.

[47] It depends on one's point of view whether the difference due to the two water vapor continuum absorption models is considered as an uncertainty or an improvement. If the MT CKD 1.0 algorithm is an improvement, then of course, all former radiative transfer calculations based on CKD have to be reconsidered. However, one point cannot be answered in the context of this work. Clough et al. [2005] elucidate: "The data used to develop the new continuum model have come predominantly from spectral atmospheric measurements. Only cases for which the characterization of the atmosphere state has been highly scrutinized have been used." The question is now: How much residual aerosol radiative properties from the Southern Great Plains or other ARM sites have been incorporated into the continuum model?

\section{Uncertainty of Humidity Profiles}

[48] Water vapor is the most important trace gas in the atmosphere and uncertainties in its vertical distribution are expected to have a big impact on radiative transfer calculations. The various instruments (frost point, Lyman- $\alpha$, radiosonde, lidar, satellite borne) operated to measure atmospheric water vapor content are described in detail in the SPARC (Stratospheric Processes and their Role in Climate) report on the assessment of upper tropospheric and stratospheric water vapor [Kley et al., 2000]. They found that generally all instruments, but radiosondes, agree within $10 \%$ of mixing ratio for altitudes between 1 and $50 \mathrm{hPa}$ and 60 and $100 \mathrm{hPa}$ pressure level, respectively. Radiosonde measurements are essentially useless in the stratosphere.

[49] From the different types of radiosonde humidity sensors, only thin-film capacitors known as humicap are suited for the upper troposphere, although measurement quality degrades in cold and dry conditions [Elliot and Gaffin, 1991; Wang et al., 2003]. Leiterer et al. [1997] list the accuracy of different humicap sensors under laboratory conditions. Relative humidity of $40 \%$ is incorrect at air temperature $-60^{\circ} \mathrm{C}$ for the Vaisala $\mathrm{RS} 80$-A sonde by $-15 \%$ and the RS80-H by $-5 \%$.

[50] The improvement by the Vaisala RS90 radiosonde was shown by Cimini et al. [2002]. They found by launching dual ascents that both pairs of RS80-H and pairs of RS90 are self-consistent, with an accuracy of mainly smaller than 1\%-point in relative humidity. The standard deviation for pairs of RS80-H is about 3\%-points and better for pairs of RS90 sondes. However, the RS80-H is drier about 3\%-points than the RS90. Nagel et al. [2001] compared a humidity profile obtained by the RS90 to lidar measurements and found agreement of the mean differences of $5 \%$ relative humidity.

[51] Different methods of correcting the measurement errors of the Vaisala radiosondes were developed, where each type of radiosonde requires a correction scheme of its own [Wang et al., 2002; Leiterer et al., 1997]. Microwave radiometer measurements of precipitable water vapor are used by the Atmospheric Radiation Measurement ARM Program to correct RS80-H radiosonde humidity by scaling [Turner et al., 2003].

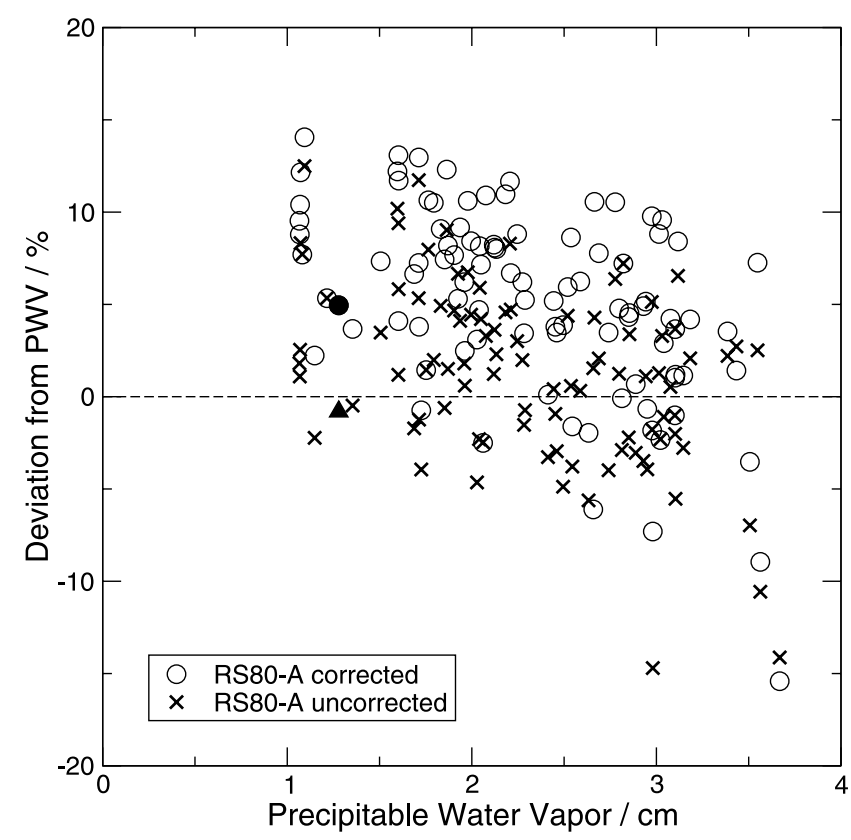

Figure 10. Deviation of precipitable water vapor of humidity profiles measured by Vaisala RS80-A radiosondes from that of a microwave radiometer. Measurements by the DWD at the Lindenberg Observatory between 21 July and 13 August. Correction of humidity [Leiterer et al., 1997] by open circles and without correction by crosses. The full symbols denote a profile discussed by Nagel at al. [2001].

[52] In order to estimate error margins of humidity profiles for radiative transfer calculations, PWV was calculated from RS80-A radiosonde data recorded by the DWD at the Lindenberg Observatory between 21 July and 13 August. The deviation of PWV from the one by a microwave radiometer is shown in Figure 10. Circles correspond to the humidity correction developed by Leiterer et al. [1997] and crosses show the uncorrected data.

[53] Apparently, most of the radiosonde profiles are associated with more PWV than the microwave radiometer measured. Notice that there is a moist bias in the figure, in particular for the smaller PWV values. The variation within the PWV of the radiosonde profiles in Figure 10 is about $\pm 7 \%$ for the drier conditions with $1 \mathrm{~cm} \mathrm{PWV} \mathrm{and} \mathrm{about} \pm 9 \%$ for $3 \mathrm{~cm}$ PWV. Of course the measurement errors of both radiosondes and radiometer are included in the figure. Thus a reasonable uncertainty scenario in radiative transfer calculations could be given by scaling humidity density profiles by $\pm 5 \%$ for both the troposphere and the stratosphere.

[54] The impact of a humidity uncertainty of $\pm 5 \% \mathrm{PWV}$ on radiative transfer is shown for different pressure-temperature profiles and different humidity loadings in Figures 11a and $11 \mathrm{~b}$. The effect of different uncertainty assumptions is presented in section 8 taking into account improvements of humidity measuring instruments, e.g., the transition from RS80 to RS92 in operational observations is just a question of time.

[55] The impact on zenith radiance in Figure 11a and on brightness temperature at TOA in Figure 11b look similar at first glance, except for the different units. Calculations were 

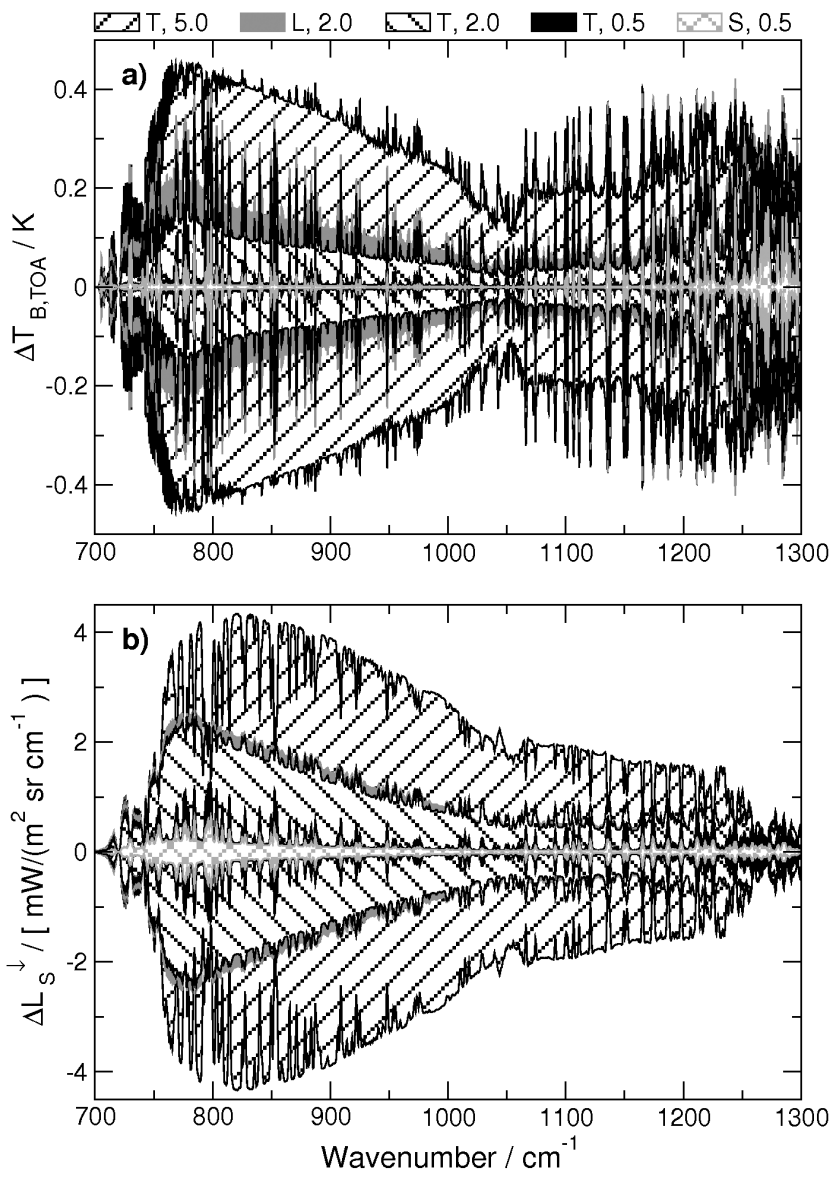

Figure 11. Radiative uncertainty at the surface due to the uncertainties of atmospheric humidity profiles given by a $\pm 5 \%$ variation of the precipitable water vapor. The density profiles of water vapor of the tropics (T), at LACE (L), and the subarctic winter (S) were scaled to the PWV (unit: $\mathrm{cm}$ ) values given in the legend. The spectra are convolved with the Blackman-Harris 4 terms function. (a) Uncertainty of the difference of brightness temperature at TOA and the convolution for IASI. (b) Uncertainty of downward radiance at the surface and the convolution for OASIS.

performed for the tropical standard atmosphere with water vapor density profile scaled to $\mathrm{PWV}$ of $5 \mathrm{~cm}$ giving the warmest and most humid conditions used in the figures. Intermediate conditions were set up for the LACE and tropical atmosphere by scaling to $2 \mathrm{~cm}$ PWV. The driest profiles are for the tropics and the subarctic winter with $0.5 \mathrm{~cm}$ PWV. The uncertainties shown in the figures are BH4 convolved spectra of line-by-line calculated radiance for ARIES/OASIS and IASI, respectively. The uncertainty ranges in the figures were arranged such that the smaller ones cover the larger ones.

[56] Apparently, the strongest impact is due to the absolute humidity. The most outstanding uncertainty is for the tropical atmosphere with $5 \mathrm{~cm}$ PWV, followed by the intermediate ones. The effect for the two atmospheres with $0.5 \mathrm{~cm}$ PWV is small. The difference between the different pressure-temperature profiles for equal PWV amounts is apparent by the widths of the gray filled patterns. The smallness of the widths indicates that the $\mathrm{p}-\mathrm{T}$ dependence is of minor importance. Altogether, the detection of aerosols should be more difficult for humid atmospheres. More details are given in section 8 .

\section{Uncertainty of Ozone Profiles}

[57] Measuring atmospheric ozone profiles was subject to recent validation campaigns. Ozone profiles by sondes, lidar systems, and the SAGE II instrument were intercompared at the Mauna Loa Observatory [McPeters et al., 1999]. The WMO Jülich Ozone Sonde Intercomparison Experiment (JOSIE) compared all operational types of ozonesondes in a controlled environmental chamber simulating real flight conditions [Smit and Kley, 1998]. Assessments of long-term trends in the vertical distribution of ozone including characteristics of the instruments and those of the data analysis methods are given in a WMO report [Harris et al., 1998].

[58] Ozonesondes operate between the surface and the balloon burst altitude at about $35 \mathrm{~km}$. The accuracy of sonde measurements degrades above altitudes of $28 \mathrm{~km}$ due to the pump efficiency correction of the controlled flow of air through an aqueous chemical sensing element. The vertical resolution by sondes is about $100 \mathrm{~m}$. The one by lidar systems ranges from $\approx 0.5 \mathrm{~km}$ at altitude $20 \mathrm{~km}$ and 4 to $7 \mathrm{~km}$ at $50 \mathrm{~km}$.

[59] The accuracy of ECC ozonesondes is about $5-10 \%$ in the troposphere. Comparisons of ozonesondes in the stratosphere with other ozone profiling techniques show agreement of about $\pm(3-5) \%$ at altitudes between the tropopause and $28 \mathrm{~km}$ [Harris et al., 1998]. Thus a worst case uncertainty of $\pm 10 \%$ can be considered.

[60] The uncertainty of the zenith radiance at the surface and of the nadir brightness temperature at TOA is shown for the LACE atmosphere in Figures 12a and 12b. Additionally, the density of ozone was varied separately in the troposphere and stratosphere giving a hint, where the highest uncertainty appears. Apparently, the uncertainty of $\mathrm{L}^{\downarrow}$ at the surface is highest with about $\pm 5 \%$; it is mainly caused by the tropospheric ozone. Uncertainties at TOA are higher than $1 \mathrm{~K}$ for most parts of the $9.6 \mu \mathrm{m}$ ozone band.

[61] Small, more transparent microwindows are present in the monochromatic spectra (not resolved in the figure) in the lobes and in particular in the center of the band, with minimum uncertainties of about $\pm 0.1 \mathrm{~K}$ for $\mathrm{T}_{\mathrm{B}}$ and of $\pm 0.1 \mathrm{~mW} /\left(\mathrm{m}^{2} \mathrm{sr} \mathrm{cm}^{-1}\right)$ for $\mathrm{L}^{\downarrow}$ giving instruments with high spectral resolution a better chance to detect aerosols within the $9.6 \mu \mathrm{m}$ ozone band. However, these microwindows are almost closed in the convolved spectra for ARIES/OASIS and IASI, respectively.

\section{Synthesis of Uncertainties}

[62] In the previous sections, assessed or specified uncertainties of the major variables in radiative transfer were used to compute the related deviations of radiances. These related deviations are not uncertainties in the statistical sense, i.e., standard deviations. The transformation of the standard deviation of the distribution of a variable, e.g., humidity, to the marginal distributions of radiance by analytical means is not feasible. One way out are costly Monte Carlo 

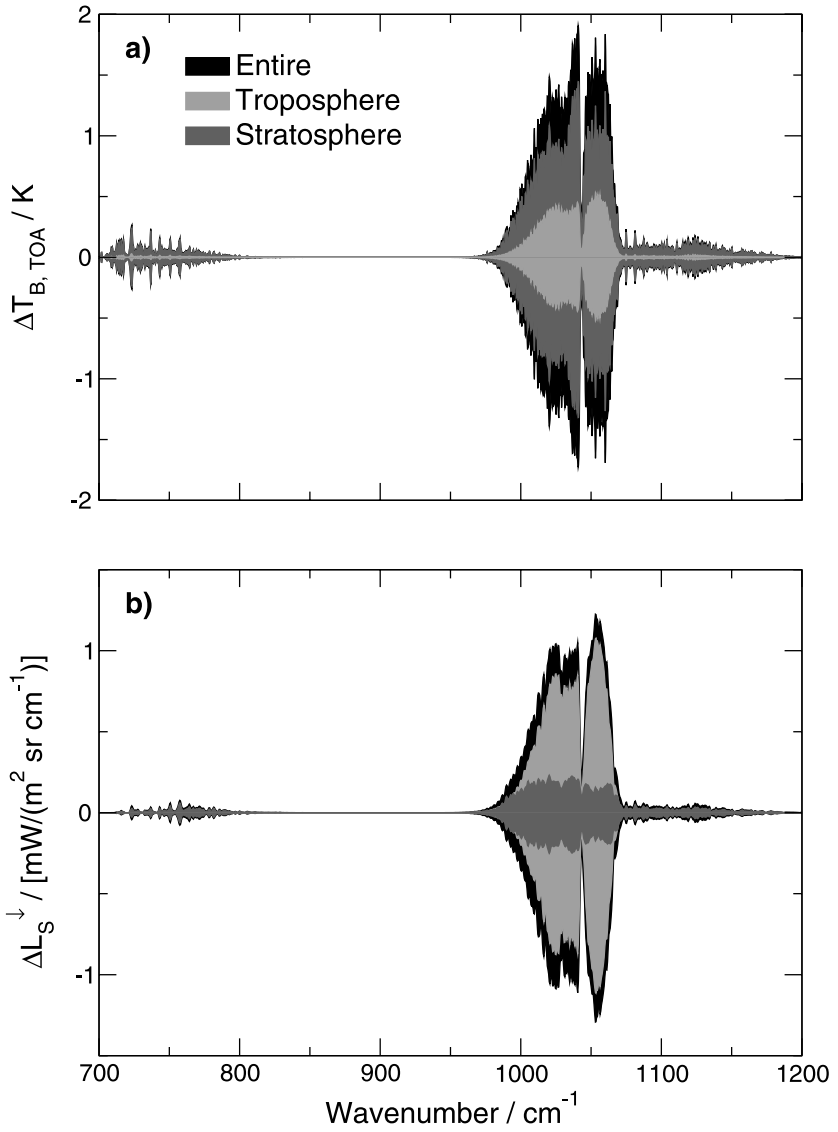

Figure 12. Uncertainty of radiative transfer due to a measurement uncertainty of $\pm 10 \%$ for ozone density profiles. Atmosphere from LACE on 9 August, 1648 UTC with ozone sonde from 10 August, 1045 UTC; the tropopause was at $12.5 \mathrm{~km}$. The spectra were convolved with the Blackman-Harris 4 terms function. (a) Nadir brightness temperature at TOA with the convolution for IASI. (b) Zenith radiance at the surface with the convolution for OASIS.

calculations. Another approach is the linearization of the radiative transfer equation from a Taylor series expansion with subsequent error propagation calculations. For the latter, the independence of the variables governing radiative transfer has to be given because the covariances have to vanish. This restricts to spectral ranges with weak absorption, i.e., generally outside of the centers of strong absorption lines. However, considerations with respect to aerosol properties would obviously not be done in ranges of small transmission.

[63] From textbooks on statistics, the function of a normal distribution is again a normal distribution and the total distribution of multiple random variables is given by the convolution integral, if the random variables are independent of each other. The total variance of a normal distribution is given by the sum of the variances of the marginal distributions. In analogy, we calculate the total uncertainty of radiance by the square root of the sum of the squared radiative uncertainties due to the measurement accuracy of humidity profiles, the one of ozone content, and for the HITRAN line parameters derived in the previous sections.
These uncertainties are only valid outside the centers of strong absorption lines.

[64] The uncertainty by the water vapor continuum algorithm is left out because it could only be discussed as the difference between two methods. It is, as well as the uncertainty due to measurement errors of ARIES and OASIS, discussed further below.

[65] A high radiative uncertainty is introduced by the measurement accuracy of atmospheric humidity profiles, for which different levels of measurement accuracy were considered: from $\pm 5 \%$, which is adequate for radiosonding, in steps to $\pm 1 \%$, a high demand on measurements. Also, because of the impact of absolute humidity on the uncertainty, two scenarios are considered: the LACE atmosphere from 9 August, 1648 UTC with $1.46 \mathrm{~cm}$ precipitable water vapor and the same atmosphere, but the relative humidity
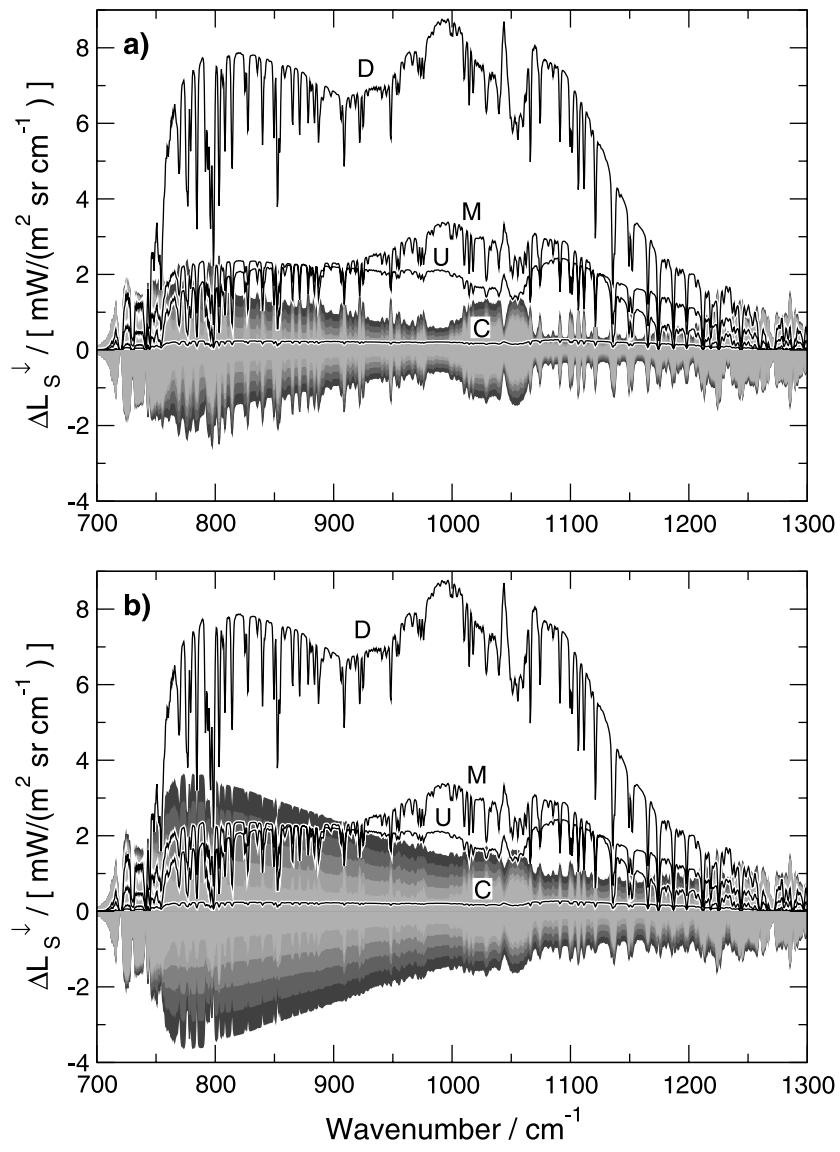

Figure 13. Uncertainty of radiance at the surface in the atmospheric window due to the synthesis of the uncertainties of the HITRAN 2004 line parameters, humidity and ozone profiles. The five gray areas denote different uncertainties of humidity and ozone profiles from dark with $5 \%$ for humidity and $10 \%$ for ozone to light gray with $1 \%$ and $2 \%$, respectively. Black curves represent the expected impact of OPAC aerosol types desert (D), transported mineral aloft $(\mathrm{M})$, urban (U), and clean continental $(\mathrm{C})$. All radiances are convolved with the BH4 function. The uncertainties were calculated for the LACE atmosphere of 9 August, 1998, 1648 UTC. (a) PWV = $1.46 \mathrm{~cm}$. (b) Water vapor density profile scaled to $\mathrm{PWV}=$ $3.14 \mathrm{~cm}$. 

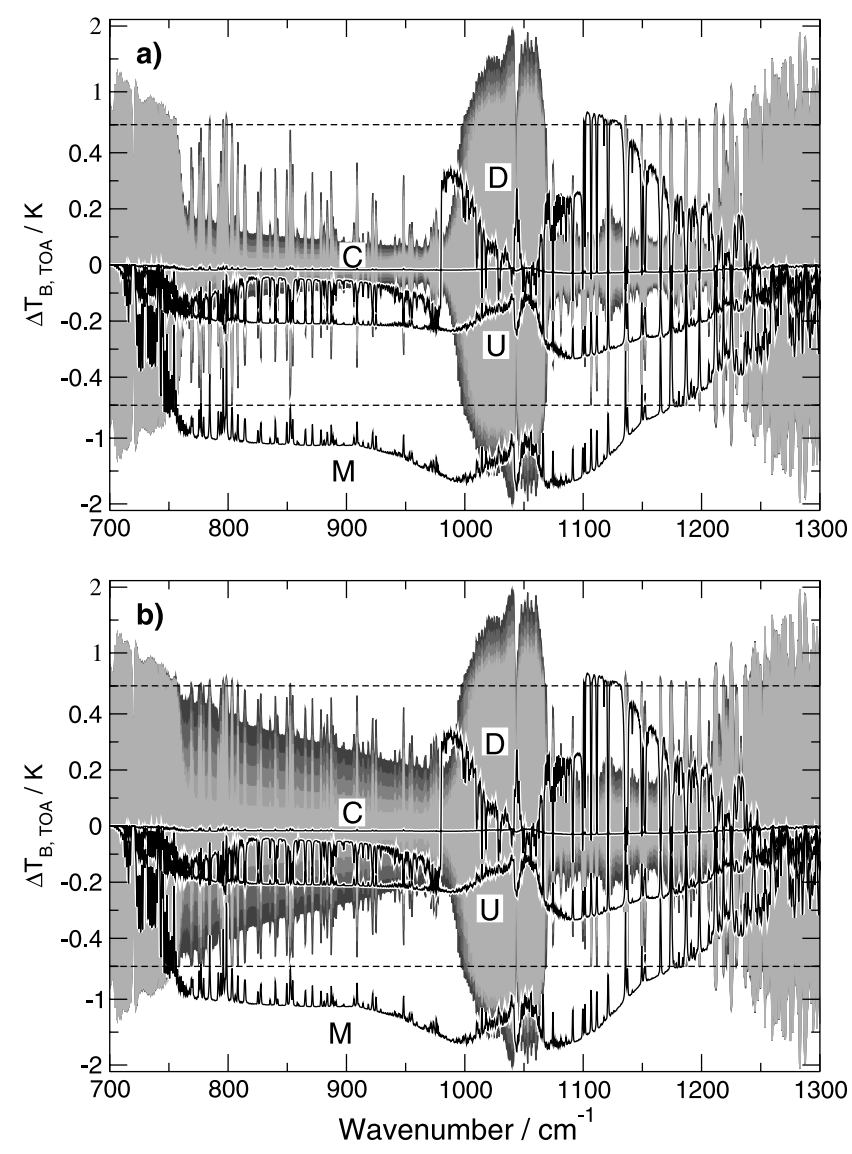

Figure 14. As Figure 13, but for the difference of brightness temperature $\Delta \mathrm{T}_{\mathrm{B}}$ at the top of the atmosphere. (a) $\mathrm{PWV}=1.46 \mathrm{~cm}$. (b) Water vapor density profile scaled to $\mathrm{PWV}=3.14 \mathrm{~cm}$.

set to a minimum of $75 \%$ in the lower $5 \mathrm{~km}$ giving PWV of $3.14 \mathrm{~cm}$. Similarly, the uncertainty of ozone profiles was varied between $\pm 10 \%$ and $\pm 2 \%$ in steps of $2 \%$ points.

[66] The radiative uncertainty is presented in Figure 13a for the drier conditions and in Figure $13 \mathrm{~b}$ for the more humid scenario. Both figures apply to zenith radiance at the surface with the convolution for ARIES and OASIS. Applying a $\pm 5 \%$ measurement error of humidity results in the synthesis presented by the dark gray range in the figures. Successively drawn upon this are the ranges with the uncertainties of humidity profiles decreasing in steps of $1 \%$-point down to $\pm 1 \%$ shown in the lightest gray. Additionally, the expectations for the aerosol types desert (D), transported mineral aloft (M), urban (U), and continental clean $(\mathrm{C})$ are shown in the figures.

[67] In Figure 13a, the signal of desert aerosol is clearly higher than the synthesis of radiative uncertainties of zenith radiation at the surface for both the humid and the drier atmosphere. Urban and transported mineral aloft are easier detectable in the part with higher wave numbers of the atmospheric window. For the part of the window with the smaller wave numbers, the signals do not emerge as clearly from the radiative uncertainties caused by the higher measurement uncertainties of atmospheric humidity profiles and not for the higher atmospheric water vapor loadings.
[68] Correspondingly, the uncertainties of brightness temperature at TOA are given in Figures $14 \mathrm{a}$ and $14 \mathrm{~b}$ for IASI. The picture for the uncertainties of brightness temperature at TOA is complicated by the surface reflectivity already discussed previously. The transported mineral aerosol aloft is clearly detectable from space. Urban and desert aerosols have a higher signal than the uncertainties in the shortwave part of the atmospheric window. Whether they are also detectable in the longwave part depends on the humidity of the profile, the measurement accuracy, and on the impact of aerosols.

[69] The signals of clear continental (and of maritime; not shown) air are hardly detectable neither from space nor from the surface. Also, for nadir viewing from space, detection in the $9.6 \mu \mathrm{m}$ ozone bands appears to be problematic. The detection of aerosols is even more difficult than suggested by the figures because the shown expectations for aerosol impact can be identified with measurements having no bias and no noise. In fact, one has to add the noise of $\pm 0.35 \mathrm{~mW} /$ $\left(\mathrm{m}^{2} \mathrm{sr} \mathrm{cm}^{-1}\right)$ for OASIS onto the curves in Figures 13a and $13 \mathrm{~b}$. Respectively, a range of brightness temperature of approximately $\pm(0.25-0.4) \mathrm{K}$ for clear-sky scenes in Figure $14 \mathrm{a}$ and $14 \mathrm{~b}$ according to the performance of IASI (http://www.esa.int/export/esaME $\rightarrow$ Instruments $\rightarrow$ IASI $\rightarrow$ Performance).

[70] Finally, to bring into relation the residual between FTIR measurements and modeling shown in Figure 1, which gave the impetus of this work, to Figure 13a: it compares to the curve for urban aerosol in its magnitude but with differences in the shape.

\section{Summary}

[71] The uncertainties of radiative transfer calculations and FTIR measurements have been assessed in the thermal infrared. The results were set in contrast to the impact on radiative transfer by aerosols typical in global modeling calculated on the basis of the optical depths taken from the OPAC software. Also, the measurement accuracy of the FTIR radiometers ARIES and OASIS operating groundbased were considered.

[72] Table 1 presents the radiative flux densities at the ground and at TOA, respectively, for three subintervals in the atmospheric window summarizing the spectral results. The climatological expectations for aerosols is spanned by the range of flux densities between the maritime and desert aerosol types. Additionally, the residual between real measurements by ARIES and OASIS from radiative transfer calculations, corresponding to Figure 1, is given. On the other hand, the measurement accuracy of interferometers in the IR is assessed by the difference between the recordings of the two FTIR instruments ARIES and OASIS. In conjunction with these, the modeling uncertainties by the HITRAN 2004 line parameters, the assessment for the water vapor continuum absorption, and the impact by measurement accuracies of atmospheric profiles were considered.

[73] It depends on the aerosol type, the assumptions used for the assessment of modeling uncertainties, the spectral interval considered, and the accuracy of the atmospheric profiles used for the assessment, whether the radiative signal of a particular aerosol type emerges from the modeling uncertainties. For the HITRAN error 
Table 1. Uncertainties of Radiative Flux Densities, $\mathrm{W} / \mathrm{m}^{2}$, for Downward at the Surface $\Delta \mathrm{F}^{\downarrow}$ and Upward at the Top of the Atmosphere $\Delta \mathrm{F}^{\uparrow}$ in Comparison to Climatological Expectations for Aerosol Types in Three Spectral Subintervals of the Atmospheric Window

\begin{tabular}{|c|c|c|c|c|c|c|}
\hline \multirow[b]{2}{*}{ Spectral Interval, $\mathrm{cm}^{-1}$} & \multicolumn{3}{|c|}{$\Delta \mathrm{F}_{\text {surface }}{ }^{\downarrow}$} & \multicolumn{3}{|c|}{$\Delta \mathrm{F}_{\mathrm{TOA}}^{\uparrow}$} \\
\hline & $800-1000$ & $1000-1700$ & $1070-1300$ & $800-1000$ & $1000-1700$ & $1070-1300$ \\
\hline \multicolumn{7}{|c|}{ Expectation for Aerosol Types } \\
\hline Desert & 6.41 & 2.07 & 3.00 & -0.28 & -0.02 & 0.07 \\
\hline Mineral transported (aloft) & 1.35 & 0.60 & 0.72 & -1.80 & -0.45 & -0.91 \\
\hline Urban & 1.94 & 0.51 & 1.22 & -0.33 & -0.06 & -0.25 \\
\hline Continental, average & 0.48 & 0.13 & 0.32 & -0.07 & -0.01 & -0.06 \\
\hline Continental, clean & 0.20 & 0.06 & 0.14 & -0.03 & -0.01 & -0.03 \\
\hline Maritime tropical & 0.14 & 0.05 & 0.13 & -0.02 & $\simeq 0$ & -0.02 \\
\hline \multicolumn{7}{|c|}{ FTIR_Simulation: LACE, 9 Aug, 1646 UTC } \\
\hline ARIES, LBL at LACE ${ }^{b, c}$ & 1.03 & 0.29 & 0.70 & - & - & - \\
\hline OASIS, LBL at LACE ${ }^{\mathrm{b}, \mathrm{c}}$ & 1.17 & 0.33 & 0.75 & - & - & - \\
\hline \multicolumn{7}{|c|}{ Uncertainty by FTIR (LACE) } \\
\hline OASIS - ARIES ${ }^{b, c}$ & 0.19 & 0.04 & 0.14 & - & - & - \\
\hline \multicolumn{7}{|c|}{ Uncertainty by Line-by-line Model } \\
\hline HITRAN '04, upper, T & \pm 0.32 & \pm 0.21 & \pm 0.62 & \pm 0.15 & \pm 0.36 & \pm 0.52 \\
\hline HITRAN '04, lower, T & \pm 0.15 & \pm 0.10 & \pm 0.30 & \pm 0.07 & \pm 0.17 & \pm 0.25 \\
\hline HITRAN ’04, upper, L & \pm 0.37 & \pm 0.30 & \pm 0.69 & \pm 0.12 & \pm 0.34 & \pm 0.46 \\
\hline HITRAN '04, lower, L & \pm 0.18 & \pm 0.14 & \pm 0.33 & \pm 0.06 & \pm 0.16 & \pm 0.22 \\
\hline HITRAN '04, upper, S & \pm 0.09 & \pm 0.13 & \pm 0.25 & \pm 0.02 & \pm 0.13 & \pm 0.14 \\
\hline HITRAN '04, lower, S & \pm 0.05 & \pm 0.06 & \pm 0.12 & \pm 0.01 & \pm 0.06 & \pm 0.07 \\
\hline $\mathrm{H}_{2} \mathrm{O}$ Continuum Abs., $\mathrm{T}^{\mathrm{c}, \mathrm{d}}$ & 0.37 & 0.23 & 0.51 & 0.04 & 0.02 & 0.11 \\
\hline $\mathrm{H}_{2} \mathrm{O}$ Continuum Abs., $\mathrm{L}^{\mathrm{c}, \mathrm{d}}$ & 0.14 & 0.07 & 0.21 & 0.04 & 0.01 & 0.05 \\
\hline $\mathrm{H}_{2} \mathrm{O}$ Continuum Abs., $\mathrm{S}^{\mathrm{c}, \mathrm{d}}$ & 0.10 & 0.01 & 0.03 & 0.01 & $\simeq 0$ & $\simeq 0$ \\
\hline \multicolumn{7}{|c|}{ Uncertainty by Atmospheric Density Profiles } \\
\hline $\left.\mathrm{H}_{2} \mathrm{O}: \pm 5 \%, \mathrm{~T}, \mathrm{PWV} 4.20 \mathrm{~cm}\right)$ & \pm 2.00 & \pm 0.42 & \pm 0.83 & \pm 0.36 & \pm 0.04 & \pm 0.20 \\
\hline $\left.\mathrm{H}_{2} \mathrm{O}: \pm 5 \%, \mathrm{~L}, 1.46 \mathrm{~cm}\right)$ & \pm 0.90 & \pm 0.12 & \pm 0.38 & \pm 0.16 & \pm 0.01 & \pm 0.11 \\
\hline $\left.\mathrm{H}_{2} \mathrm{O}: \pm 5 \%, \mathrm{~S}, 0.42 \mathrm{~cm}\right)$ & \pm 0.10 & \pm 0.01 & \pm 0.06 & $\simeq 0$ & $\simeq 0$ & \pm 0.01 \\
\hline $\mathrm{O}_{3}: \pm 10 \%, \mathrm{~L}, 288 \mathrm{DU}$ & \pm 0.02 & \pm 0.20 & \pm 0.02 & \pm 0.03 & \pm 0.26 & \pm 0.05 \\
\hline
\end{tabular}

${ }^{a}$ Details see subsections. The \pm symbols denote averaged uncertainty ranges. Notation for atmospheres: tropical (T), LACE (L) from Lindenberg, 9 August, 1648 UTC, and subarctic winter (S).

${ }^{\mathrm{b}}$ Assumption of isotropic radiation.

${ }^{\mathrm{c}}$ Absolute values.

${ }^{\mathrm{d}}$ The difference by the MT_CKD minus CKD algorithm.

coding, it is unknown how the uncertainties of the single line parameters distribute into the range between the lower and upper boundaries of the error coding. Hence a refinement of the error coding table would sharpen the range of uncertainty. The water vapor continuum absorption, in particular the MT_CKD code, is based on modeling and on real atmo-spheric measurements, thus incorporating uncertainties of various kinds. The impact on the radiative uncertainty by the atmospheric profiles depends on the measurement accuracy of the profiles. The uncertainties of the flux densities based on the accuracy of the humidity profiles shown in Table 1 are calculated with the assumption of a $\pm 5 \%$ measurement accuracy; they scale approximately linearly with the percentage measurement accuracy of the density profiles for each interval and profile.

[74] The actual accuracy of a measured atmospheric profile of humidity and ozone varies from case to case. Different from that, the uncertainties due to the HITRAN database, the water vapor continuum absorption algorithm, and systematic measurement errors by the instrument give a systematic bias. This bias is of unknown magnitude and sign.

[75] The uncertainties in measurements by the FTIR instruments ARIES and OASIS are generally small compared to the magnitude of uncertainties in radiative transfer modeling (available only for the LACE atmosphere). However, in cases of small aerosol impact on measured radiance spectra, it is necessary to reduce the noise by either averaging an ensemble of spectra and/or by the average within microwindows to be specified for a spectrum, thus reducing the resolution.

[76] The detection of aerosols from radiance spectra appears easier in the atmospheric window for the shorter wavelengths outside the $9.6 \mu \mathrm{m}$ ozone band. Uncertainties of upward radiation also depend on the reflectivity of the surface. From the aerosol types given in the OPAC climatology, the desert aerosol, and with reservation the mineral transported and urban aerosols, has expected radiative signals clearly larger than the modeling uncertainties in the atmospheric window for downward radiation. Similarly, only the signal of transported mineral aloft emerges clearly from the uncertainties of upward radiation.

[77] The measurement accuracy of humidity and ozone profiles by the radiosondes considered in this study is not sufficient to detect small aerosol optical depths. However, it has to be stated quite clearly that climatologically distributed aerosols have experienced mixing and depletion over a long period. The origin of most aerosols is given by small scale plumes or sporadic events, where concentrations can be expected to be much higher and then, the aerosol impact 
could exceed more clearly the uncertainties in radiative transfer modeling and FTIR observations making the detection easier.

[78] Acknowledgments. Thanks are due to Ulrich Leiterer and Horst Dier (DWD) for reprocessing the radiosonde profiles from the LACE campaign. Jürgen Güldner (DWD) is thanked for providing the microwave precipitable water vapor data from LACE.

\section{References}

Ansmann, A., U. Wandinger, A. Wiedensohler, and U. Leiterer (2002), Lindenberg Aerosol Characterization Experiment 1998 (LACE 98): Overview, J. Geophys. Res., 107(D21), 8129, doi:10.1029/ 2000JD000233.

Bakan, S., J. Schlicht, H.-D. Hollweg, and L. Fiedler (2001), Remote sensing of temperature and atmospheric constituents from surface based FTIR measurements, in IRS 2000: Current Problems in Atmospheric Radiation, edited by W. L. Smith and Y. M. Timofeyev, pp. 11251128, Deepak, Hampton, Va.

Cimini, D., E. R. Westwater, and B. Lesht (2002), Evaluation of the improvements in humidity sounding by balloon-borne sensors, paper presented at 1st COST720 Workshop on Integrated Ground-Based Remote Sensing Stations for Atmospheric Profiling, Eur. Coop. in the Field of Sci. and Tech. Res., l'Aquila, Italy, $19-21$ June . (Available at http:// www.cost720.rl.ac.uk)

Clough, S. A., F. X. Kneizys, and R. W. Davies (1989), Line shape and the water vapor continuum, Atmos. Res., 23, 229-241.

Clough, S. A., M. J. Iacono, and J.-L. Moncet (1992), Line-by-line calculations of atmospheric fluxes and cooling rates: Application to water vapor, J. Geophys. Res., 97, 15,761-15,785.

Clough, S. A., M. W. Shephard, E. J. Mlawer, J. S. Delamere, M. J. Iacono, K. Cady-Pereira, S. Boukabara, and P. D. Brown (2005), Atmospheric radiative transfer modeling: A summary of the AER codes, J. Quant. Spectrosc. Radiat. Transfer, 91, 233-244.

Ellingson, R. G., and W. J. Wiscombe (1996), The spectral radiance experiment (SPECTRE): Project description and sample results, Bull. Am. Meteorol. Soc., 77, 1967-1985.

Elliot, W. P., and D. J. Gaffin (1991), On the utility of radiosonde humidity archives for climate studies, Bull. Am. Meteorol. Soc., 72, 1507-1520.

Harris, F. J. (1978), On the use of windows for harmonic analysis with the Discrete Fourier Transform, Proc. IEEE, 66, 51-83.

Harris, N., R. Hudson, and C. Phillips (Eds.) (1998), SPARC/IOC/GAW assessment of trends in the vertical distribution of ozone, Rep. 43, World Meteorol. Org., Geneva.

Haywood, J. M., S. R. Osborne, P. N. Francis, A. Keil, P. Formenti, M. O. Andreae, and P. H. Kaye (2003), The mean physical and optical properties of regional haze dominated by biomass burning aerosol measured from the C-130 aircraft during SAFARI 2000, J. Geophys. Res., 108(D13), 8473, doi:10.1029/2002JD002226.

Hess, M., P. Koepke, and I. Schult (1998), Optical properties of aerosols and clouds: The software package OPAC, Bull. Am. Meteorol. Soc., 79, $831-844$.

Highwood, E. J., J. M. Haywood, M. D. Silverstone, S. Newman, and J. P. Taylor (2003), Radiative properties and direct effect of Saharan dust measured by the C-130 aircraft during Saharan Dust Experiment (SHADE): 2. Terrestrial spectrum, J. Geophys. Res., 108(D18), 8578, doi:10.1029/2002JD002552.

Hollweg, H.-D. (1993), A k-distribution method considering centres and wings of atmospheric absorption lines, J. Geophys. Res., 98, 2747-2756.

Intergovernmental Panel on Climate Change (2001), Climate Change 2001: The Scientific Basis, edited by J. T. Houghton et al., 881 pp., Cambridge Univ. Press, New York.

Kley, D., , J. M. Russel, and C. Phillips (Eds.) (2000), SPARC assessment of upper tropospheric and stratospheric water vapour, WCRP 113, TD 1043, SPARC Rep. 2, 312 pp. World Meteorol. Org., Geneva.

Leiterer, U., H. Dier, and T. Naebert (1997), Improvements in radiosonde humidity profiles using RS80/90 radiosondes of Vaisala, Contrib. Atmos. Phys., 70, 319-336.
Léon, J.-F., D. Tanré, J. Pelon, Y. J. Kaufman, J. Haywood, and B. Chatenet (2003), Profiling of a Saharan dust outbreak based on a synergy between active and passive remote sensing, J. Geophys. Res., 108(D18), 8575, doi:10.1029/2002JD002774.

Lubin, D., and A. S. Simpson (1994), The longwave emission signature of urban pollution: Radiometric FTIR measurement, Geophys. Res. Lett., $21,37-40$.

Luther, F. M., and Y. Fouquart (1984), The Intercomparison of Radiation Codes in Climate Models (ICRCCM), WMO-WCRP, Frascati, Italy, 15 18 August

Markowicz, K. M., P. J. Flatau, A. M. Vogelmann, P. K. Quinn, and E. J. Welton (2003), Clear-sky infrared aerosol radiative forcing at the surface and the top of the atmosphere, Q. J. R. Meteorol. Soc., 129, 2927-2947.

McClatchey, R. A., R. W. Fenn, J. E. A. Selby, F. E. Volz, and J. S. Garing (1978), Optical properties of the atmosphere, in Handbook of Optics, pp. $1-65$, sec. 14, McGraw-Hill, New York.

McPeters, R. D., et al. (1999), Results from the 1995 stratospheric ozone profile intercomparison at Mauna Loa, J. Geophys. Res., 104, 30,50530,514 .

Nagel, D., U. Leiterer, H. Dier, A. Kats, J. Reichardt, and A. Behrendt (2001), High accuracy humidity measurements using the standardized frequency method with a research upper-air sounding system, Meteorol. Z., $10,395-405$.

Revercomb, H. E., H. Buijs, H. B. Howell, D. D. LaPorte, W. L. Smith, and L. A. Sromovsky (1988), Radiometric calibration of IR Fourier transform spectrometers: Solution to a problem with the High-Resolution Interferometer Sounder, Appl. Opt., 27, 3210-3218.

Ridgway, W. L., Harshvardhan, and A. Arking (1991), Computation of atmospheric cooling rates by exact and approximate methods, J. Geophys. Res., 96, 8969-8984

Rothman, L. S., et al. (2005), The HITRAN 2004 molecular spectroscopic database, J. Quant. Spectrosc. Radiat. Transfer., 96, 139-204.

Smit, H. G. J., and D. Kley (1998), Jülich Ozone Sonde Intercomparison Experiment (JOSIE), WMO Global Atmos. Watch Rep. Ser., vol. 130, World Meteorol. Org., Geneva.

Sokolik, I. N., D. M. Winkler, G. Bergametti, D. A. Gilette, G. Carmichael, Y. F. Kaufman, L. Gomes, L. Schuetz, and J. E. Penner (2001), Introduction to special section: Outstanding problems in quantifying the radiative impacts of mineral dust, J. Geophys. Res., 106, 18,015-18,027.

Spänkuch, D., W. Döhler, and J. Güldner (2000), Effect of coarse biogenic aerosol on downwelling infrared flux at the surface, J. Geophys. Res., $105,17,341-17,350$.

Tjemkes, S. A., et al. (2003), The ISSWG line-by-line inter-comparison experiment, J. Quant. Spectrosc. Radiat. Transfer, 77, 433-453.

Turner, D. D., B. M. Lesht, S. A. Clough, J. C. Liljegren, H. E. Revercomb, and D. C. Tobin (2003), Dry bias and variability in Vaisala RS80-H radiosondes: The ARM experience, J. Atmos. Oceanic Technol., 20, $117-132$.

Wang, J., H. L. Cole, D. J. Carlson, E. R. Miller, K. Beierle, A. Paukkunen, and T. K. Laine (2002), Corrections of humidity measurement errors from the Vaisala RS80 radiosonde: Application to TOGA COARE data, J. Atmos. Oceanic Technol., 19, 981-1002.

Wang, J., D. J. Carlson, D. B. Parson, T. F. Hock, D. Lauritsen, H. L. Cole, K. Beierle, and E. Chamberlain (2003), Performance of operational radiosonde humidity sensors in direct comparison with a chilled mirror dewpoint hygrometer and its climate implications, Geophys. Res. Lett., 30(16), 1860, doi:10.1029/2003GL016985.

Wilber, A. C., D. P. Kratz, and S. K. Gupta (1999), Surface emissivity maps for use in satellite retrievals of longwave radiation, NASA/TP-1999. 209362, 30 pp., NASA, Washington, D. C.

Wilson, S. H. S., N. C. Atkinson, and J. A. Smith (1999), The development of an airborne infrared interferometer for meteorological sounding studies, J. Atmos. Oceanic Technol., 16, 1912-1927.

S. Bakan and H.-D. Hollweg, Max Planck Institute for Meteorology, Bundesstr. 53, D-20146 Hamburg, Germany. (bakan@dkrz.de; hollweg@ dkrz.de)

J. P. Taylor, Met Office, FitzRoy Road, Exeter, Devon, EX1 3Pb, UK. (jonathan.p.taylor@metoffice.gov.uk) 